\title{
Microvirgula aerodenitrificans gen. nov., sp. nov., a new Gram-negative bacterium exhibiting co-respiration of oxygen and nitrogen oxides up to oxygen-saturated conditions
}

\author{
Dominique Patureau, Jean-Jacques Godon, Patrick Dabert, \\ Théodore Bouchez, Nicolas Bernet, Jean Philippe Delgenes \\ and René Moletta
}

Author for correspondence: Dominique Patureau. Tel: +334684251 69. Fax: +33468425160 .
e-mail: patureau@ensam.inra.fr

Institut National de la Recherche Agronomique, Laboratoire de Biotechnologie de l'Environnement (LBE). Avenue des Etangs, 11100 Narbonne, France

\begin{abstract}
A denitrifier micro-organism was isolated from an upflow denitrifying filter inoculated with an activated sludge. The cells were Gram-negative, catalaseand oxidase-positive curved rods and very motile. They were aerobic as well as anoxic heterotrophs that had an atypical respiratory type of metabolism in which oxygen and nitrogen oxides were used simultaneously as terminal electron acceptors. The $\mathrm{G}+\mathrm{C}$ content was $65 \mathrm{~mol} \%$. Our isolate was phenotypically similar to Comamonas testosteroni, according to classical systematic classification systems. However, a phylogenetic analysis based on the 165 rRNA sequence showed that the aerobic denitrifier could not be assigned to any currently recognized genus. For these reasons a new genus and species, Microvirgula aerodenitrificans gen. nov., sp. nov., is proposed, for which SGLY2 ${ }^{\top}$ is the type strain.
\end{abstract}

Keywords: Microvirgula aerodenitrificans gen. nov., sp. nov., co-respiration of oxygen and nitrogen oxides, Proteobacteria, fluorescent in situ hybridization, oligonucleotide probes

\section{INTRODUCTION}

The denitrifiers are facultative anaerobic bacteria that can adjust their metabolic pathway to the prevailing growth conditions. Under aerobic conditions, the most efficient electron acceptor is oxygen. During anoxic conditions, a lower free-energy transducing pathway is used, the denitrification pathway, reducing nitrate to $\mathrm{N}_{2}$ gas. It had been believed for a long time that denitrifying activity and enzyme synthesis were completely repressed by oxygen (11). However, some micro-organisms, like Thiosphaera pantotropha, isolated from activated sludge, can reduce oxygen and nitrate simultaneously to water and $\mathrm{N}_{2}$, respectively, up to oxygen-saturated conditions $(21,22,23)$. A strain was isolated in our laboratory from an upflow

Abbreviations: DAPI, 4',6-diamidino-2-phenylindole; TRITC, tetramethylrhodamine 5-isothiocyanate.

The GenBank accession number for the nearly complete sequence (nt 9-1509) of the 16S rRNA gene reported in this paper is U89333. denitrifying filter. It exhibits an atypical behaviour towards oxygen and nitrate (16), since it is able to corespire oxygen and nitrogen oxides and produce $\mathrm{N}_{2}$. This behaviour has been explained by the continuous expression of denitrifying enzymes whatever the aeration conditions (17). This strain, named SGLY2, has been tentatively characterized as Comamonas testosteroni by phenotypic characterization. In this paper, we compare the phenotypic and phylogenetic characterization of this new bacterium and present the design of a specific oligonucleotide probe for strain detection by fluorescent in situ hybridization. On the basis of these studies we propose a new genus and species, Microvirgula aerodenitrificans gen. nov., sp. nov., to describe this bacterium.

\section{METHODS}

Bacterial strains and culture conditions. The strain used in this study was isolated from an upflow anoxic filter previously inoculated with activated sludge. The filter was maintained under anoxic conditions to remove nitrogen pol- 
lution. However, the anoxic conditions were not strict. Part of the filter sludge was used to inoculate another reactor that was submitted to alternate aerobic and anoxic conditions to enrich the population in aerobic denitrifiers. SGLY2 ${ }^{\mathrm{T}}$ was isolated from this reactor by spreading on nitrate complete medium (Merck) under aerobic conditions. Then the strain was cultivated at $35^{\circ} \mathrm{C}$ and $\mathrm{pH} 7$ under aerobic as well as anoxic conditions in synthetic medium containing $0.01 \mathrm{M}$ potassium phosphate buffer, $\mathrm{pH} 7 \cdot 0$, $380 \mathrm{mg} \mathrm{MgSO}_{4} \mathrm{l}^{-1}, 250 \mathrm{mg}$ yeast extract $\mathrm{l}^{-1},\left(\mathrm{NH}_{4}\right)_{2} \mathrm{SO}_{4}$ as nitrogen source $\left(116 \mathrm{mg} \mathrm{N} 1^{-1}\right), \mathrm{KNO}_{3}, \mathrm{KNO}_{2}$ or $\mathrm{N}_{2} \mathrm{O}$ as electron acceptor $\left(250 \mathrm{mg} \mathrm{N} \mathrm{1}^{-1}\right)$, succinate or acetate as electron donor $\left(500 \mathrm{mg} \mathrm{C} \mathrm{^{-1 }}\right)$ and $1 \mathrm{ml}$ trace element solution $\mathrm{l}^{-1}(15)$. Cultures were grown either in batch culture (in $120 \mathrm{ml}$ Penicillin flasks) or in a continuous stirred reactor under various dissolved oxygen concentrations to observe the behaviour of the strain in the presence of the two electron acceptors. Discontinuous cultures were also used (i) to test different carbon sources, electrons acceptors and sodium salt concentrations and (ii) to determine optimum growth factors $(\mathrm{pH}$, temperature) and growth inhibitors.

Escherichia coli TG1 was grown in LB (25). Other strains used to compare physiological capabilities (denitrifying ability under various aeration conditions) and/or probe specificity to the isolated strain were: Pseudomonas testosteroni $\left[\right.$ ATCC $11996^{\mathrm{T}}$; reclassified as Comamonas testosteroni (27)], Paracoccus denitrificans (NCIMB 8944), Paracoccus halodenitrificans (ATCC 25843), Pseudomonas stutzeri (ATCC 14405) and Zoogloea ramigera (ATCC 19544 ${ }^{\mathrm{N}}$ ) $\left(^{\mathrm{T}}\right.$, type strain; ${ }^{\mathrm{N}}$, neotype strain). They were all grown according to the recommendations of the American Type Culture Collection (ATCC, Rockville, MD, USA).

Morphological characteristics. Gram staining was performed as described by Magee et al. (13). Colony-forming units were observed on complete agar medium $\left(\mathrm{g}^{-1}\right.$ : yeast extract, 5 ; $\mathrm{NaCl}, 5$; pancreatic peptone, 15; agar, 18) as well as on synthetic agar medium (synthetic medium containing $18 \mathrm{~g}$ agar $1^{-1}$ ). Spore formation was determined by malachite green staining of cells grown on nutrient agar. Morphological properties were examined by phase-contrast microscopy. Transmission electron microscopy was used to examine flagellation and for cell wall characterization. Cultures $(48 \mathrm{~h}$ ) were fixed in a solution of $3 \%$ glutaraldehyde in $0.2 \mathrm{M}$ cacodylate buffer, $\mathrm{pH} 7 \cdot 4$, for $1 \mathrm{~h}$ at $4{ }^{\circ} \mathrm{C}$. The cells were centrifuged and washed three times with the same buffer. They were post-fixed with $1 \%$ osmic acid for $1 \mathrm{~h}$ at $4{ }^{\circ} \mathrm{C}$, embedded in $1.3 \%$ agar and dehydrated for $10 \mathrm{~min}$ each with 70,95 and $100 \%$ ethanol. Preparations were washed in propylene oxide for $30 \mathrm{~min}$, infiltrated with epoxy resin/propylene oxide $(1: 1)$ for $1 \mathrm{~h}$ and then embedded in $100 \%$ epoxy resin. After hardening, ultrathin sections were cut with a diamond knife, stained with uranyl acetate and Reynold's lead citrate for $20 \mathrm{~min}$ (20) and examined with a Philips EM 400 microscope.

Physiological and biochemical characteristics. Oxidase activity was determined by monitoring the oxidation of $N, N, N^{\prime}, N^{\prime}$-tetramethyl- $p$-phenylenediamine on filter paper. Catalase activity was detected by production of bubbles after addition of $3 \%$ hydrogen peroxide on fresh colonies. Two systems of phenotypic characterization were used: API 20 NE (bioMérieux) and the Biolog Microstation System. The former makes a comparison of the carbon assimilation pattern (12 carbon sources) and of eight conventional tests of the unknown strain relative to a database containing essentially Gram-negative, clinical non-enterobacteria. The latter is based on the comparison of the oxidation pattern of
95 carbon sources of the unknown strain relative to a database containing those of previously identified bacteria, including non-clinical strains.

Ethanol, glycerol, testosterone, succinate, acetate, propionate, butyrate and valerate were also tested as electron donors for denitrification (final concentration in synthetic medium: $500 \mathrm{mg} \mathrm{C}^{-1}$ ). The denitrifying potential of the strain was evaluated through consumption of nitrogen oxides (nitrate, nitrite and $\mathrm{N}_{2} \mathrm{O}$ ) and production of $\mathrm{N}_{2} \mathrm{O}$ and $\mathrm{N}_{2}$.

$16 S$ rDNA sequence analysis. The $16 \mathrm{~S}$ rRNA gene (rDNA) sequence of strain SGLY $2^{\mathrm{T}}$ was determined by sequencing of PCR-amplified 16S rDNA. Genomic DNA extraction, PCR-mediated amplification of 16S rDNA and purification of the PCR products were performed by using previously described protocols $(7,25)$. The primers used for PCR were 9F (5' GAGTTTGATCMTGGCTCAG) and 1509R (5' GNTACCTTGTTACGACTT) (7). Purified PCR products were sequenced by using a PRISM Ready Reaction DyeDeoxy Terminator Cycle Sequencing Kit (Applied Biosystems). Sequence reaction mixtures were electrophoresed with an Applied Biosystems model 373A DNA sequencer. The 16S rDNA sequence of the new strain was compared with all accessible $16 \mathrm{~S}$ rDNA sequences in databases. The alignment of $16 \mathrm{~S}$ rDNA sequences with representative organisms belonging to the $\beta$-subclass of the Proteobacteria was obtained by using CLuSTAL v software (10). Phylogenetic trees were calculated by Jukes-Cantor (12) and neighbourjoining algorithms (24).

Dot blot hybridization. RNAs from pure cultures of Paracoccus halodenitrificans, Zoogloea ramigera, Comamonas testosteroni, Paracoccus denitrificans, Pseudomonas stutzeri and $E$. coli were extracted by a low-pH hot-phenol extraction procedure (19). RNA was denatured as previously described (25). Approximately $1 \mu \mathrm{g}$ of each extract was deposited as a dot on a nylon membrane (Hybond- $\mathrm{N}^{+}$; Amersham) and linked to the membrane by UV exposure with a Spectrolinker XL-1000 (Spectronics).

The following oligonucleotide probes complementary to specific regions of $16 \mathrm{~S} \mathrm{rRNA}$ were used for hybridization : (i) S-D-Bact-0338-a-A-18 is specific for the Bacteria domain (26); (ii) S-*-Mae-0636-a-A-18 is complementary to positions 636-653 (E. coli numbering) (5) of the SGLY2 ${ }^{\mathrm{T}} 16 \mathrm{~S}$ rRNA (this work). Non-radioactive labelling of oligonucleotides was performed with the DIG Oligonucleotide 3'End Labelling Kit according to the manufacturer's instructions (Boehringer Mannheim). Hybridization and stripping of the membrane were performed as recommended by Boehringer Mannheim (4). Hybridization was revealed by chemiluminescence using anti-digoxigenin/alkaline phosphatase antibodies and CDP-star substrate with Kodak XOMAT AR film.

In situ hybridization. The two oligonucleotides described above were synthesized and 5'-labelled with fluorescein or rhodamine derivatives using an aminolynk and subsequently purified by acrylamide gel electrophoresis (Eurogentec).

Fixation of exponentially growing cells with $4 \%$ paraformaldehyde and whole-cell in situ hybridization were performed as described elsewhere (3). Dual staining of cells with 4',6-diamidino-2-phenylindole (DAPI) and fluorescent oligonucleotides was performed by addition of $0.33 \mu \mathrm{g}$ DAPI ml $\mathrm{m}^{-1}$ in the hybridization washing buffer. Samples were mounted in Citifluor antifading fluid. The optimal hybridization stringency for the oligonucleotide probe S-*-Mae-0636-a-A-18 was determined by quantification of 
the fluorescence conferred by the probe to target and nontarget reference cells at different formamide concentrations in the hybridization buffer as described previously (28). Slides were examined with an Olympus BX60 microscope fitted with a $100 \times$ plan fluorite objective. The microscope was equipped with U-MWU, U-MWB and U-MWG filter sets. Images were captured with a black-and-white video camera (LH 750 LL, Lhesa Electronique) of high sensitivity $\left(10^{-4}\right.$ lux $)$. Semiautomatic thresholding and edge detection was performed by the Idra image analysis program (Ides). At least 300 cells were analysed for each hybridization condition and the mean values of triplicate measurements were determined.

\section{RESULTS AND DISCUSSION}

\section{Morphological characteristics}

Strain SGLY2 ${ }^{\mathrm{T}}$ is a very motile, curved-rod-shaped, Gram-negative, non-spore-forming bacterium. Cell size and organization are dependent on the growth stage: cells are thin and single initially but are larger and associated ( $4-5$ cells) by late stationary phase (Fig. 1). On complete agar medium, the strain grows as translucent round colonies. On synthetic agar medium under anoxic conditions, visible colonies appear after $48 \mathrm{~h}$ incubation. They are circular $(0.5-1 \mathrm{~mm}$ diam.), well-separated and cream-coloured.

\section{Phenotypic characteristics}

Strain SGLY2 ${ }^{\mathrm{T}}$ is an heterotrophic micro-organism able to grow under aerobic and anoxic conditions with various carbon sources. It requires amino acids and vitamins for growth. Under anoxic conditions, nitrate, nitrite or $\mathrm{N}_{2} \mathrm{O}$ are used as alternative electron acceptors to oxygen to produce $\mathrm{N}_{2}$. The maximum growth rate $\left(\mu_{\max }\right)$ differs with the aeration conditions: the strain grows three to four times more rapidly in the presence of oxygen than in the presence of nitrate with $\mu_{\max }$ values of 0.37 and $0.11 \mathrm{~h}^{-1}$, respectively. In fact, the value of $\mu_{\max }$ increases from its lowest under strictly anoxic conditions to mixed nitrate/oxygen conditions and to its highest under strictly oxic conditions.

The temperature range for growth is $15-45^{\circ} \mathrm{C}$, maximal growth occurring at $35^{\circ} \mathrm{C}$, and the strain does not grow at $55^{\circ} \mathrm{C}$ independent of the aeration conditions used. Growth is observed between $\mathrm{pH} 6$ and but the optimum $\mathrm{pH}$ is 7 under aerobic and anoxic conditions.

Strain SGLY2 ${ }^{\mathrm{T}}$ oxidizes a variety of organic compounds as determined by the Biolog test, including organic acids, amino acids and Tween 40 and 80 . Sugars are not oxidized as well as some organic acids, e.g. citric acid, D-galacturonic acid and D-gluconic acid (Table 1).

The Biolog Microstation System identified the strain as Comamonas sp. This identification was based on the two criteria of similarity index and distance index $(0 \cdot 81$ and $0 \cdot 11$, respectively) between SGLY $2^{\mathrm{T}}$ and the type strain Comamonas testosteroni. The next closest species type strain was Alcaligenes faecalis type II, though this was quite distant. The identification as Comamonas
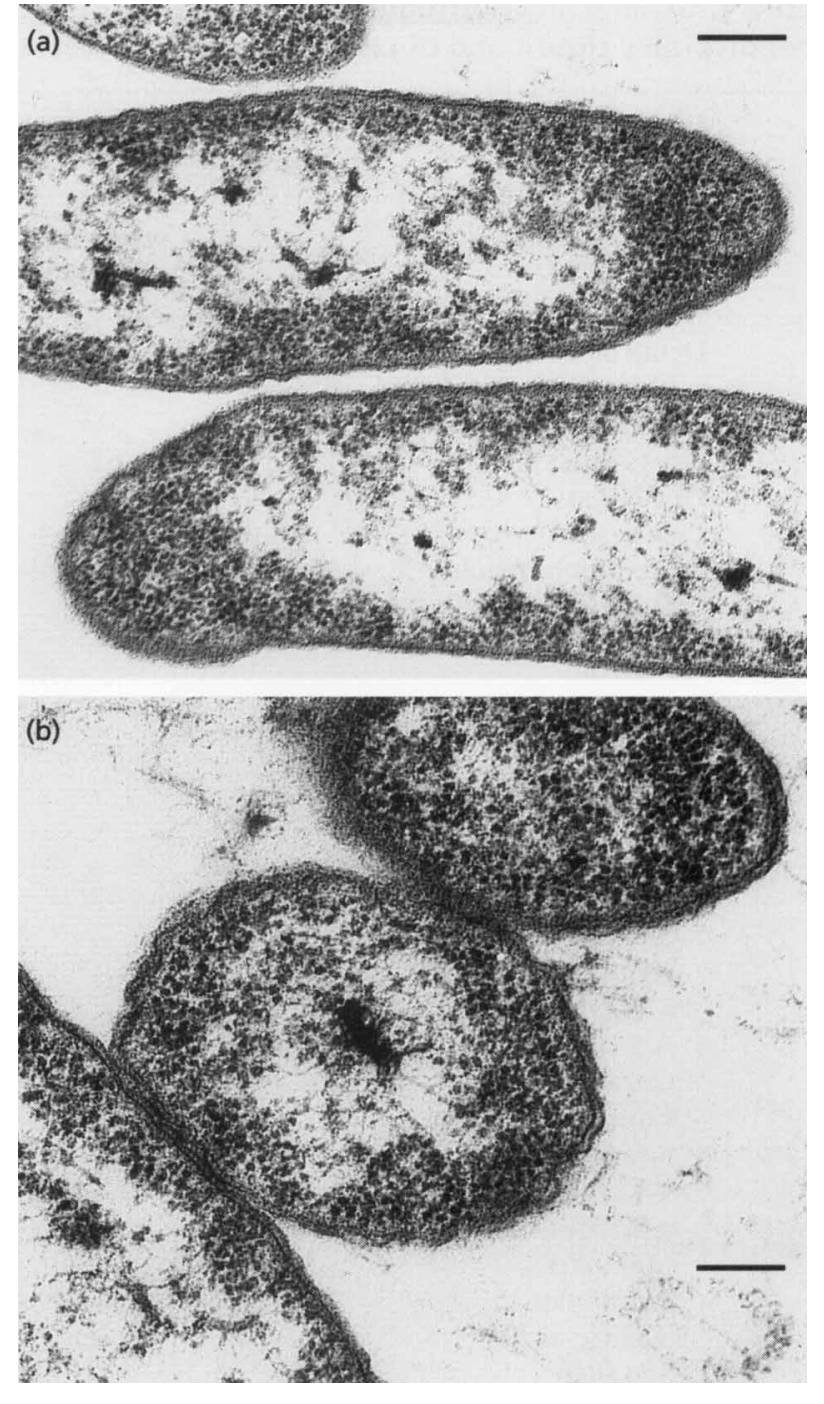

Fig. 1. Transmission electron micrographs of a thin section of cells of Microvirgula aerodenitrificans showing the Gramnegative cell wall, the presence of numerous flagella and the curved rod morphology. Bars, $0.12 \mu \mathrm{m}$ (a) and $0.08 \mu \mathrm{m}$ (b).

testosteroni was confirmed by the API 20 NE identification system.

The physiological and nutritional characteristics of strain SGLY2 ${ }^{\mathrm{T}}$, Comamonas testosteroni and Alcaligenes faecalis are listed in Table 1 . It should be noted that in spite of their nearly identical carbon source utilization pattern, SGLY $2^{\mathrm{T}}$ differs from Comamonas testosteroni in its ability to denitrify. Also of note was the inability of Comamonas testosteroni to oxidize acetate, ethanol, glycerol and L-asparagine compared to SGLY2 ${ }^{\mathrm{T}}$. In contrast, Alcaligenes faecalis was able to reduce nitrite anoxically, but not nitrate.

\section{Aerobic denitrification}

$\mathrm{SGLY}^{\mathrm{T}}$ is an atypical denitrifying bacterium compared to classical denitrifiers because of its particular mechanism of respiration in the presence of oxygen 
Table 1. General and nutritional characteristics of the study strain, $\mathrm{SGLY}^{\top}$ and comparison with those of phenotypically closest and of phylogenetically closest strains $(8,9)$

\begin{tabular}{|c|c|c|c|c|c|c|}
\hline \multirow[t]{2}{*}{ Characteristic } & \multirow[t]{2}{*}{$\begin{array}{c}\text { Strain } \\
\text { SGLY2 }^{\mathrm{T}}\end{array}$} & \multicolumn{2}{|c|}{$\begin{array}{l}\text { Phenotypically closest } \\
\text { strains }\end{array}$} & \multicolumn{3}{|c|}{ Phylogenetically closest strains } \\
\hline & & $\begin{array}{c}\text { Comamonas } \\
\text { testosteroni }\end{array}$ & $\begin{array}{c}\text { Alcaligenes } \\
\text { faecalis }\end{array}$ & $\begin{array}{l}\text { Zoogloea } \\
\text { ramigera }\end{array}$ & $\begin{array}{c}\text { Chromobacterium } \\
\text { violaceum }\end{array}$ & $\begin{array}{l}\text { Vogesella } \\
\text { indigofera }\end{array}$ \\
\hline \multicolumn{7}{|l|}{ Denitrification: } \\
\hline Nitrate $\rightarrow$ nitrite & + & - & - & + & + & + \\
\hline Nitrite $\rightarrow \mathrm{N}_{2}$ & + & - & + & + & + & + \\
\hline $\mathrm{G}+\mathrm{C}(\mathrm{mol} \%)$ & 65 & 62 & $55 \cdot 9-59 \cdot 4$ & $65 \cdot 3$ & $65-68$ & $65 \cdot 4$ \\
\hline Growth at $45^{\circ} \mathrm{C}$ & + & - & ND & ND & - & ND \\
\hline Lipase activity & + & + & - & - & - & ND \\
\hline \multicolumn{7}{|l|}{ Oxidation of (Biolog): } \\
\hline Dextrin & - & - & - & ND & - & ND \\
\hline Glycogen & - & - & - & - & - & ND \\
\hline L-Arabinose & - & - & - & - & - & - \\
\hline D-Fructose & - & - & - & - & + & - \\
\hline D-Galactose & - & - & - & - & - & - \\
\hline$\alpha$-D-Glucose & - & - & - & - & + & - \\
\hline$\alpha$-Lactose & - & - & - & - & - & ND \\
\hline Maltose & - & - & - & - & \pm & ND \\
\hline Sorbitol & - & - & - & ND & $\overline{ \pm}$ & ND \\
\hline Sucrose & - & - & - & - & - & - \\
\hline Xylitol & - & - & ND & ND & ND & ND \\
\hline Methylpyruvate & + & + & ND & + & ND & ND \\
\hline Acetate & + & - & + & + & \pm & ND \\
\hline Citrate & - & + & + & + & + & - \\
\hline Formate & + & + & ND & ND & - & ND \\
\hline$\beta$-Hydroxybutyrate & + & + & + & + & ND & ND \\
\hline$\alpha$-Ketoglutarate & - & + & ND & + & ND & ND \\
\hline$\alpha$-Ketovalerate & - & + & ND & ND & ND & ND \\
\hline Malonate & - & - & + & ND & - & ND \\
\hline Propionate & + & + & + & + & ND & - \\
\hline Sebacic acid & + & + & - & ND & ND & ND \\
\hline Succinate & + & + & + & + & ND & ND \\
\hline D-Alanine & - & - & + & ND & ND & + \\
\hline L-Asparagine & + & - & ND & ND & ND & ND \\
\hline L-Aspartic acid & + & + & + & ND & ND & ND \\
\hline L-Glutamic acid & + & + & ND & ND & ND & ND \\
\hline L-Leucine & + & + & + & ND & - & ND \\
\hline L-Phenylalanine & - & - & + & ND & + & ND \\
\hline L-Proline & + & + & + & ND & \pm & + \\
\hline D-Serine & - & - & ND & ND & $\overline{N D}$ & $\mathrm{ND}$ \\
\hline L-Threonine & - & - & ND & ND & ND & ND \\
\hline D,L-Carnitine & - & - & ND & ND & ND & ND \\
\hline Inosine & - & - & ND & ND & ND & ND \\
\hline Uridine & - & - & ND & ND & ND & ND \\
\hline Glycerol & + & - & ND & ND & - & \pm \\
\hline 2,3-Butanediol & - & - & ND & ND & ND & $\overline{\mathrm{ND}}$ \\
\hline Glucose 1-phosphate & - & - & ND & ND & ND & ND \\
\hline \multicolumn{7}{|l|}{ Assimilation of (API): } \\
\hline Caprate & + & + & $\mathrm{ND}$ & ND & ND & ND \\
\hline Adipate & - & + & ND & ND & ND & ND \\
\hline Malate & + & + & ND & ND & ND & ND \\
\hline \multicolumn{7}{|l|}{ Growth on: } \\
\hline Ethanol & + & - & ND & - & ND & + \\
\hline Testosterone & + & + & ND & ND & ND & - \\
\hline
\end{tabular}

ND, Not determined. 


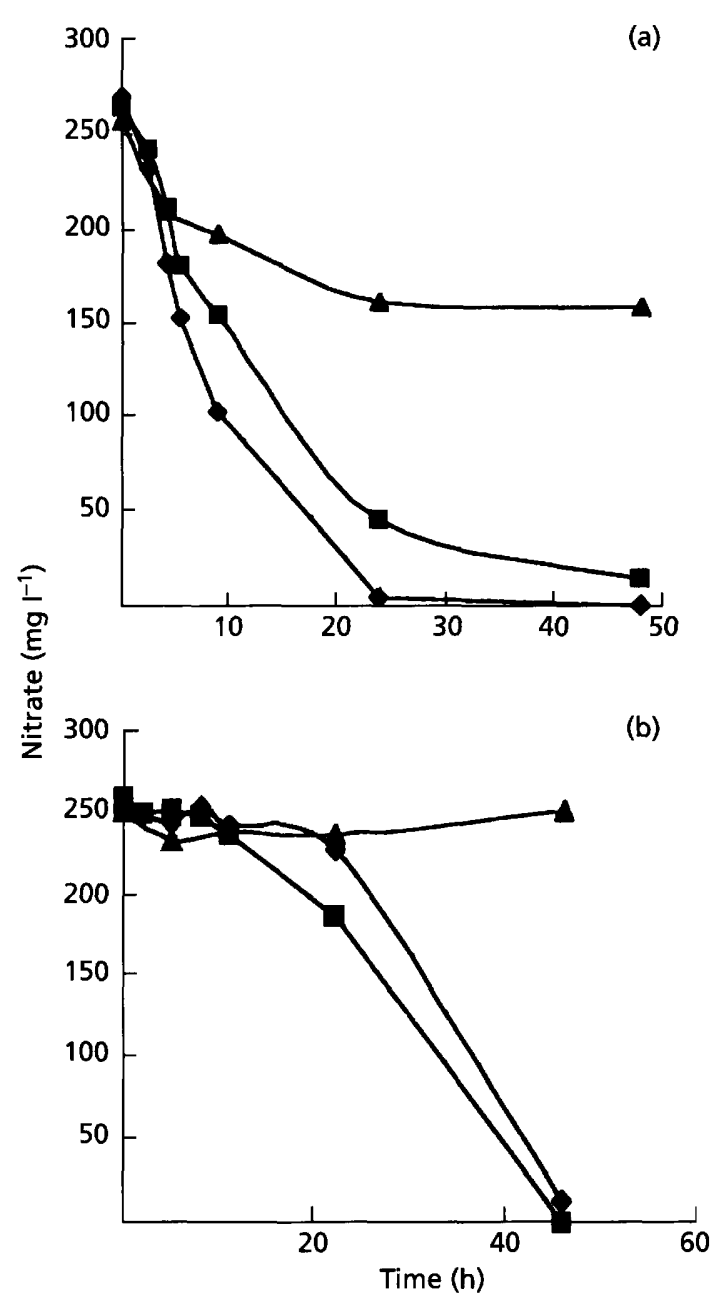

Fig. 2. Nitrate reduction in discontinuous culture under aerated conditions with Microvirgula aerodenitrificans (a) and comparison with Paracoccus denitrificans under the same culture conditions (b). $\square$, Anoxic conditions obtained by sparging synthetic medium with argon; $\bullet$, partial aerobic conditions obtained by addition of pure oxygen at the start of the culture following sparging with argon; $\boldsymbol{\Delta}$, aerobic conditions obtained by continuous presence of air. All experiments were performed in Penicillin flasks closed with a rubber stopper.

and nitrogen oxides. Fig. 2 shows the nitrate consumption of $\mathrm{SGLY}^{\mathrm{T}}$ and Paracoccus denitrificans (NCIB 8944) under different aeration conditions. Whatever the aeration conditions used, the reduction of nitrate by SGLY $2^{\mathrm{T}}$ was immediate. In contrast, the reduction of nitrate by Paracoccus denitrificans began with a lag phase under anoxic and partial aerobic conditions, and no reduction was observed under fully aerobic conditions. Again, compared to the behaviour of Paracoccus denitrificans under the same culture conditions, it appeared that SGLY $2^{\mathrm{T}}$ was able to corespire oxygen and nitrate up to oxygen-saturated conditions and was able to produce $\mathrm{N}_{2}$ (Fig. 3). These properties were observed under discontinuous as well as continuous culture, implying activity and synthesis

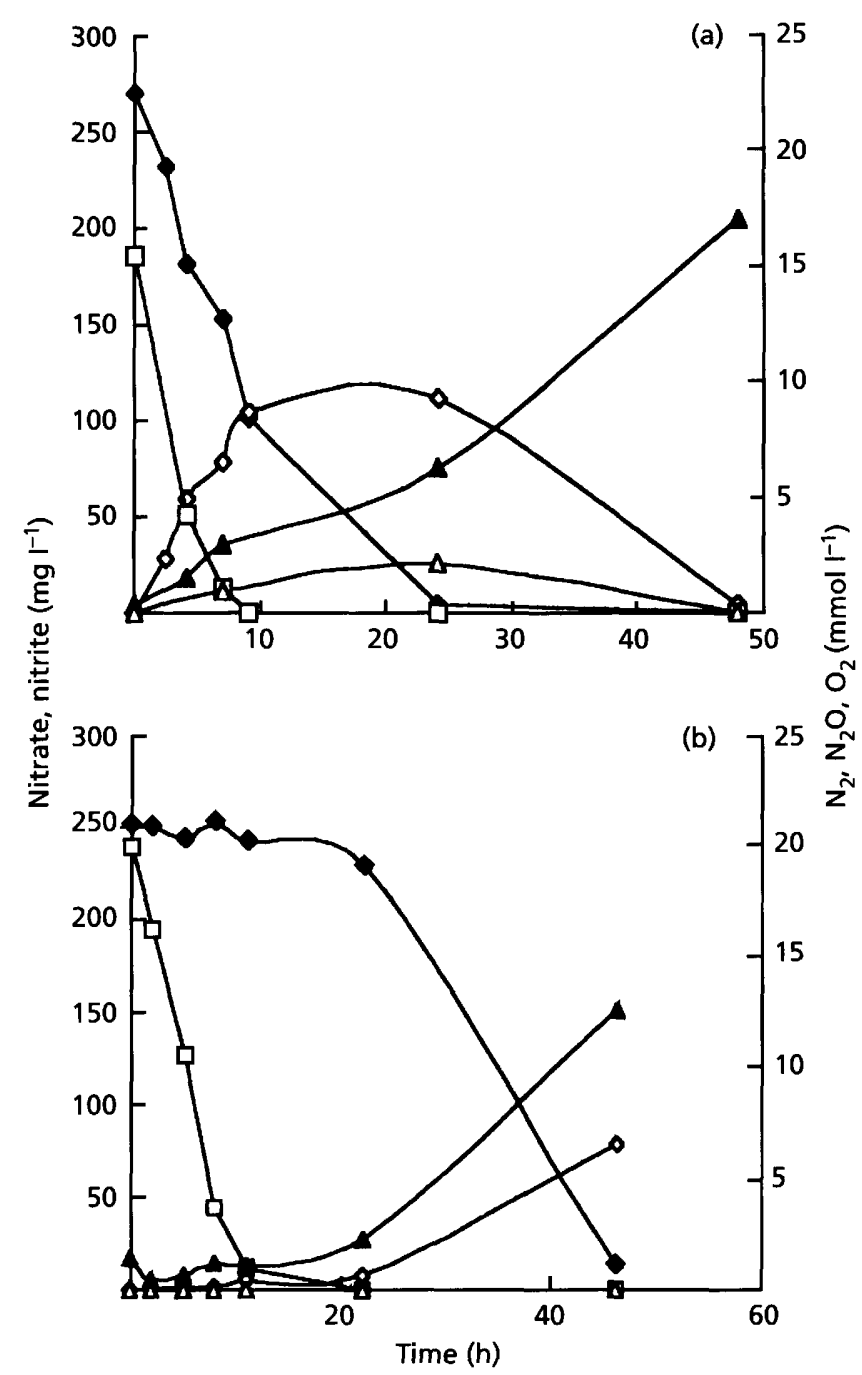

Fig. 3. Demonstration of co-respiration of oxygen and nitrate under partial aerobic conditions with Microvirgula aerodenitrificans (a) and comparison with Paracoccus denitrificans under the same culture conditions (b). Evolution of oxygen $(\square)$, nitrogen $(\Delta)$ and $\mathrm{N}_{2} \mathrm{O}(\triangle)$ in the gaseous phase; evolution of nitrate $(\diamond)$ and nitrite $(\diamond)$ in the liquid phase.

of the four denitrifying enzymes of the strain whatever the aeration conditions (17). The same behaviour has been observed with other micro-organisms such as Thiosphaera pantotropha(23) and Alcaligenes faecalis (22). However, these differ from SGLY $2^{\mathrm{T}}$ because they are also considered to be heterotrophic nitrifiers: no heterotrophic nitrification was observed with SGLY$2^{\mathrm{T}}$.

Aerobic denitrification gives an opportunity to create a new global nitrogen removal process where nitrification and denitrification could occur simultaneously in a single aerated unit (16).

\section{Phylogenetic characterization}

16S rDNA sequence analysis unambiguously placed $\mathrm{SGLY}^{\mathrm{T}}$ in the $\beta$-subclass of the Proteobacteria. 


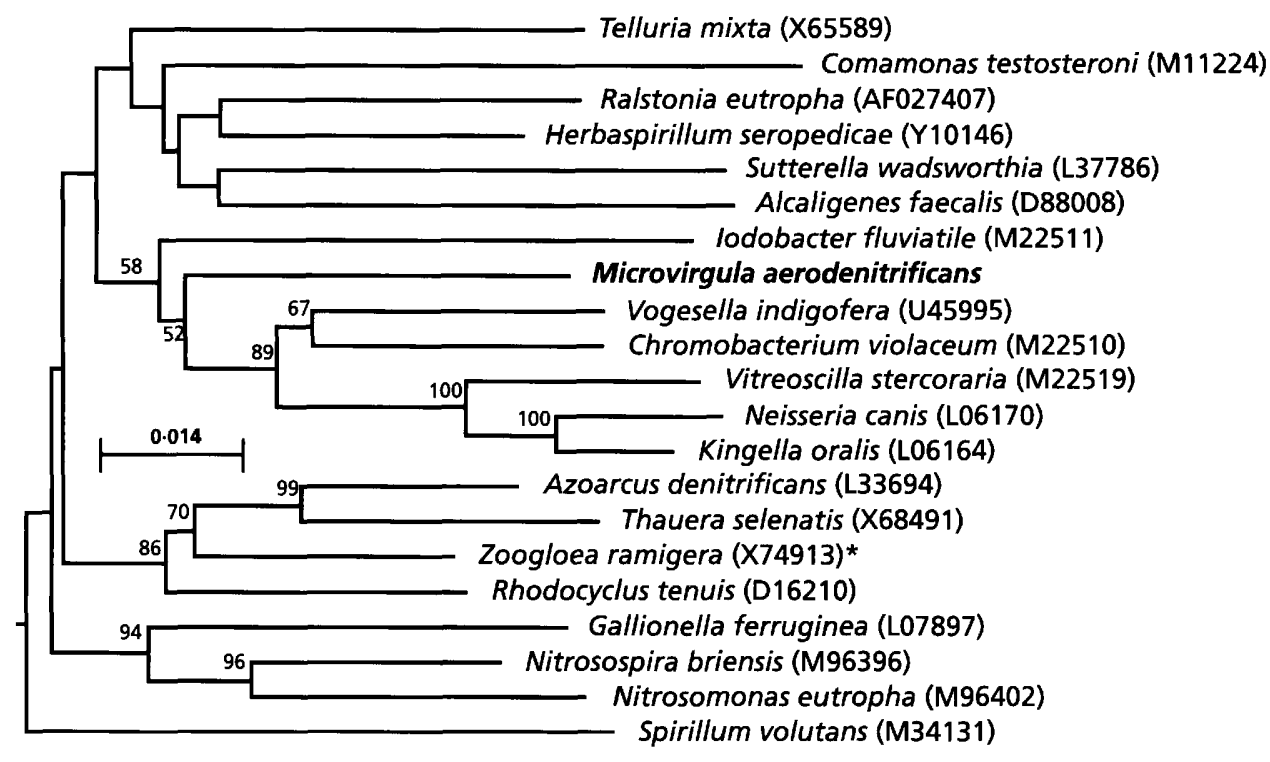

Fig. 4. Phylogenetic tree showing the relationship of Microvirgula aerodenitrificans gen. nov., sp. nov. to the other members of the $\beta$-subclass of the Proteobacteria. This tree was inferred from 16S rRNA sequence data by the neighbourjoining method (24). A total of 1120 nucleotide positions were included in the analysis. The tree was rooted with the sequence of Paracoccus denitrificans. The scale bar indicates the percentage difference per nucleotide position using the Jukes-Cantor correction (12). Numbers refer to bootstrap values up to $50 \%$ for each node out of a total of 500 replicate samplings (6). *, Accession number corresponds to strain ATCC 19544. Names are given as cited in the GenBank database.

However, the 16S rDNA of the new isolate exhibited less than $89 \%$ sequence similarity with the $16 \mathrm{~S}$ rDNAs of all previously described members of this subclass. The closest micro-organisms, Zoogloea ramigera, Vogesella indigofera and Chromobacterium violaceum, which are also denitrifiers but differ in their carbon source assimilation pattern (Table 1), present 88.2 , 87.3 and $87.9 \%$ 16S rDNA sequence similarity, respectively. Based on phylogenetic affiliation, SGL$\mathrm{Y} 2^{\mathrm{T}}$ belongs to the Neisseria group but the bootstrap re-sampling analysis did not reveal any strong cluster affinities (Fig. 4).

We also compared the $16 \mathrm{~S}$ rDNA sequence of SGLY2 ${ }^{\mathrm{T}}$ with those of Comamonas testosteroni and Alcaligenes faecalis, the closely related micro-organisms by phenotypic characterization (see above). The sequence alignment gave 84.3 and $83.3 \%$ similarity, respectively.

Because of its interesting phenotypic characteristics and since it could not be assigned to any currently recognized genus, the aerobic denitrifier SGLY2 ${ }^{\mathrm{T}}$ should be proposed as a new genus and a new species of the $\beta$-subclass of the Proteobacteria.

\section{Design and optimization of an SGLY2 $2^{\top}$-specific oligonucleotide probe}

Fluorescent in situ hybridization with rRNA-targeted nucleic acid probes is a molecular technique allowing rapid, reliable, specific and cultivation-independent detection of bacteria in environmental samples (2, for review). Since it can be a powerful tool for identi- fication and monitoring of the strain in natural or industrial ecosystems, a specific oligonucleotide probe was designed.

A comparative analysis of the $16 \mathrm{~S}$ rDNA sequence of SGLY2 ${ }^{\mathrm{T}}$ with all other accessible $16 \mathrm{~S}$ rDNA sequences [GenBank and Ribosomal Database Project (14)] allowed the determination of a specific SGLY $2^{\mathrm{T}}$ rRNA target site. All non-target micro-organism sequences exhibited at least three differences with this site (Table 2 ). The closest match was the 16S rDNA sequence of Paracoccus halodenitrificans (ATCC 25843). The SGLY2 ${ }^{\mathrm{T}}$-specific target site was located in the V4 variable region of the 16S rRNA (positions 636-653; $E$. coli numbering) (5). An oligonucleotide complementary to this site was synthesized and named S-*Mae-0636-a-A-18 according to the Oligonucleotide Probe Database (1).

Probe specificity was assessed by dot blot hybridization with digoxigenin-labelled probe on total nucleic acid preparations of $S G L Y 2^{\mathrm{T}}$ and phylogenetically or phenotypically related strains (see Methods). The SGLY $2^{\mathrm{T}}$-targeted probe hybridized specifically to SGLY $^{\mathrm{T}}$ nucleic acid preparations while the Bacteria domain probe S-D-Bact-0338-a-A-18 showed a strong signal with all nucleic acid preparations (data not shown). Thus, the newly designed probe specifically targeted strain SGLY2 ${ }^{\mathrm{T}}$ RNA.

Fluorescent in situ hybridization conditions were optimized by hybridization of SGLY2 ${ }^{\mathrm{T}}$ and Paracoccus halodenitrificans with increasing buffer strin- 
Table 2. Difference alignment of the $16 \mathrm{~S}$ rRNA target regions of probe S-*-Mae-0636-a-A-18

\begin{tabular}{|c|c|}
\hline Strain & Target sequence* \\
\hline SGLY2T $2^{\mathrm{T}}$ & GGGAACUGCGGCCGAAACUGUCUCGCUAGAGUACGUCAGAGG \\
\hline Paracoccus halodenitrificans & $------\mathrm{A}--\mathrm{A} U---\mathrm{G}-------\mathrm{A}--------\mathrm{G}-\mathrm{A} G \mathrm{G}----$ \\
\hline Escherichia coli & $---------A U-U--U----G-A A---U----C U C G U-----$ \\
\hline Zoogloea ramigera & -------- UUU - UG $----\mathrm{CA}-\mathrm{AA}--------\mathrm{G}-\cdots--$ \\
\hline Chromobacterium violaceum & ------ G -- AUUG -- G----CACA $--------G--------$ \\
\hline Comamonas testosteroni & ------- CAUU-UG ---- CAAG ------- G -- G ----- \\
\hline Vogesella indigofera & $---\mathrm{N}------$ UUU $-\mathrm{G}----$ ACAAGA $-------\mathrm{GU}-------$ \\
\hline
\end{tabular}

* Probe target is in bold.

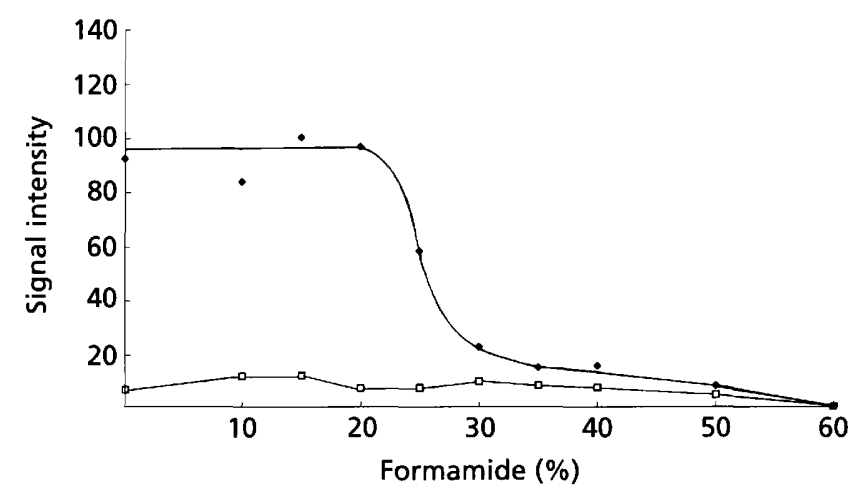

Fig. 5. Fluorescence conferred by TRITC-labelled probe S-*Mae-0636-a-A-18 to whole fixed cells of SGLY2 ${ }^{\top}(\diamond)$ and Paracoccus halodenitrificans ( $\square$ ) at different formamide concentrations.

gency and the tetramethylrhodamine 5-isothiocyanate (TRITC)-labelled SGLY $2^{\mathrm{T}}$-specific probe. As shown in Fig. 5, a specific hybridization of the probe to SGLY $2^{\mathrm{T}}$ cells was readily observed at $44^{\circ} \mathrm{C}$, but $50 \%$ dissociation of the probe required the addition of $25 \%$ formamide to the standard hybridization buffer (3). The most specific hybridization conditions were thus $44{ }^{\circ} \mathrm{C}$ and $25 \%$ formamide. With these hybridization conditions, the fluorescent probe allowed the detection of $90-98 \%$ of the SGLY $2^{\mathrm{T}}$ cells stained by DAPI. Stationary-phase culture cells exhibited a lower but still detectable signal. Mixed culture experiments showed that a specific detection of SGLY2 ${ }^{\mathrm{T}}$ was still possible when it was mixed with 1000 times more E. coli cells (data not shown).

\section{Description of Microvirgula gen. nov.}

Microvirgula (Mi.cro.vir'gu.la. Gr. adj. micros small; L. fem. n. virgula twig or rod; M.L. n. Microvirgula small twig or rod).

Gram-negative, curved-rod-shaped cells, occurring singly or in pairs, or in some cases in clusters. Very motile. Oxidase- and catalase-positive. Aerobic and chemo-organotrophic metabolism, having a large spectrum of carbon sources except sugars. Capable of anoxic growth on nitrate, nitrite and $\mathrm{N}_{2} \mathrm{O} . \mathrm{G}+\mathrm{C}$ content is $65 \mathrm{~mol} \%$. Phylogenetic position is the high$\mathrm{G}+\mathrm{C}$-content group of Gram-negative bacteria of the $\beta$-subclass of the Proteobacteria. Closest related genera are Zoogloea and Chromobacterium. The type species is Microvirgula aerodenitrificans.

\section{Description of Microvirgula aerodenitrificans sp. nov.}

Microvirgula aerodenitrificans (ae.ro.de.ni.tri'fi.cans. Gr. n. aer air; M.L. v. denitrificare to denitrify; M.L. part. aerodenitrificans denitrifying with or in air).

Morphological and chemotaxonomic characteristics are the same as those described above for the genus. Aerobic and anoxic doubling times are 1.87 and $6.3 \mathrm{~h}$, respectively. This strain is able to co-respire oxygen and nitrogen oxides under oxygen-saturated conditions and to produce $\mathrm{N}_{2}$. Can grow on acetate, succinate and propionate and on ethanol, methanol and glycerol. No growth is observed on sugars. Optimum $\mathrm{pH}$ and temperature for growth are 7 and $35^{\circ} \mathrm{C}$, respectively, under aerobic and anoxic conditions. The type strain is SGLY2 ${ }^{\mathrm{T}}$, isolated in the LBE in Narbonne.

\section{ACKNOWLEDGEMENTS}

We are especially grateful to B. Martinie, INRA Theix, for her help in electron microscopy and E. Zumstein, INRA Narbonne, for the 16S rRNA sequence determination. We thank Professor Grimont from Pasteur Institut for $\mathrm{G}+\mathrm{C}$ determination.

\section{REFERENCES}

1. Alm, E. W., Oerther, D. B., Larsen, N., Stahl, D. A. \& Raskin, L. (1996). The oligonucleotide probe database. Appl Environ Microbiol 62, 3557-3559.

2. Amann, R. I., Ludwig, W. \& Schleifer, K.-H. (1995). Phylogenetic identification and in situ detection of individual microbial cells without cultivation. Microbiol Rev 59, 143-169.

3. Amann, R. I. (1995). In situ identification of micro-organisms by whole cell hybridization with rRNA-targeted nucleic acid probes. In Molecular Microbial Ecology Manual, pp. 
1-15. Edited by A. D. Akkermans, J. D. van Elsas \& F. J. de Bruijn. Dordrecht: Kluwer Academic Publishers.

4. Boehringer Mannheim (1995). The DIG System User's Guide for Filter Hybridization.

5. Brosius, J., Dull, T. L., Sleeter, D. D. \& Noller, H. F. (1981). Gene organization and primary structure of a ribosomal RNA operon from Escherichia coli. J Mol Biol 148, 107-127.

6. Felsenstein, J. (1985). Confidence limits on phylogenies: an approach using the bootstrap. Evolution 39, 783-791.

7. Godon, J. J., Zumstein, E., Dabert, P., Habouzit, F. \& Moletta, R. (1997). Molecular microbial diversity in an anaerobic digestor as determined by small-subunit rDNA sequence analysis. Appl Environ Microbiol 63, 2802-2813.

8. Grimes, D. J., Woese, C. R., MacDonell, M. T. \& Colwell, R. R. (1997). Systematic study of the genus Vogesella gen. nov. and its type species, Vogesella indigofera comb. nov. Int $J$ Syst Bacteriol 47, 19-27.

9. Holt, J. G., Krieg, N. R., Sneath, P. H. A., Staley, J. T. \& Williams, S. T. (editors) (1994). Bergey's Manual of Determinative Bacteriology, 9 th edn. Baltimore: Williams \& Wilkins.

10. Higgins, D. G., Bleasby, A. J. \& Fuchs, R. (1992). CLUSTAL v: Improved software for multiple sequence alignment. Comput Appl Biosci 8, 189-191.

11. John, P. (1977). Aerobic and anaerobic bacterial respiration monitored by electrodes. J Gen Microbiol 98, 231-238.

12. Jukes, T. H. \& Cantor, C. R. (1969). Evolution of protein molecules. In Mammalian Protein Metabolism, pp. 21-132. Edited by H. M. Munro. New York: Academic Press.

13. Magee, C. M., Rodeheaver, G. \& Edgerton, R. F. (1975). A more reliable Gram staining technique for diagnosis of surgical infections. Am J Surg 130, 341-346.

14. Maidak, B. L., Larsen, N., McCaughey, M. J., Overbeek, R., Olsen, G. J., Fogel, K., Blandy, J. \& Woese, C. R. (1994). The Ribosomal Database Project. Nucleic Acids Res 22, 3485-3487.

15. Patureau, D., Davison, J., Bernet, N. \& Moletta, R. (1994). Denitrification under various aeration conditions in Comamonas sp., strain SGLY2. FEMS Microbiol Ecol 14, $71-78$.

16. Patureau, D., Bernet, N. \& Moletta, R. (1995). Study of the denitrifying enzymatic system of Comamonas sp., strain SGLY2, under various aeration conditions with a particular view on nitrate and nitrite reductases. Curr Microbiol 32, $25-32$.
17. Patureau, D., Bernet, N. \& Moletta, R. (1995). Effect of oxygen on denitrification in continuous chemostat culture with Comamonas sp. strain SGLY2. J Ind Microbiol 16, 124-128.

18. Patureau, D., Bernet, N. \& Moletta, R. (1995). Combined nitrification and denitrification in a single aerated reactor using the aerobic denitrifier Comamonas sp. strain SGLY2. Water Res 31, 1363-1370.

19. Raskin, L., Poulsen, L. K., Noguera, D. R., Rittmann, B. E. \& Stahl, D. (1994). Quantification of methanogenic groups in anaerobic biological reactors by oligonucleotide probe hybridization. Appl Environ Microbiol 60, 1241-1248.

20. Reynolds, E. S. (1963). The use of lead citrate at high $\mathrm{pH}$ as an electron opaque stain in electron microscopy. $J$ Cell Biol 17, 208-212.

21. Robertson, L. A., Van Niel, E. W. J., Torresmans, R. A. M. \& Kuenen, J. G. (1988). Simultaneous nitrification and denitrification in aerobic chemostat cultures of Thiosphaera pantotropha. Appl Environ Microbiol 54, 2812--2818.

22. Robertson, L. A., Cornelisse, R., De Vos, P., Hadioetomo, R. \& Kuenen, J. G. (1989). Aerobic denitrification in various heterotrophic nitrifiers. Antonie Leeuwenhoek 56, 289-299.

23. Robertson, L. A., Dalsgaard, T., Revsbech, N. P. \& Kuenen, J. G. (1995). Confirmation of 'aerobic denitrification' in batch cultures, using gas chromatography and $15 \mathrm{~N}$ mass spectrometry. FEMS Microbiol Ecol 18, 113-120.

24. Saitou, N. \& Nei, M. (1987). The neighbor-joining method: a new method for constructing phylogenetic trees. Mol Biol Evol 4, 406-425.

25. Sambrook, J., Fritsch, E. F. \& Maniatis, T. (1989). Molecular Cloning: a Laboratory Manual, 2nd edn. Cold Spring Harbor, NY: Cold Spring Harbor Laboratory.

26. Stahl, D. A. \& Amann, R. I. (1991). Development and application of nucleic acid probes in bacterial systematics. In Sequencing and Hybridization Techniques in Bacterial Systematics, pp. 205-248. Edited by E. Stackebrandt \& M. Goodfellow. Chichester: Wiley.

27. Tamaoka, J., Ha, D. M. \& Komagata, K. (1987). Reclassification of Pseudomonas acidovorans den Dooren de Jong 1926 and Pseudomonas testosteroni Marcus and Talalay 1956 as Comamonas acidovorans comb. nov. and Comamonas testosteroni comb. nov., with an emended description of the genus Comamonas. Int J Syst Bacteriol 37, 52-59.

28. Wagner, M., Rath, G., Amann, R., Koops, H.-P. \& Schleifer, K.-H. (1995). In situ identification of ammonia-oxidizing bacteria. Syst Appl Microbiol 18, 251-264. 